\title{
A Combined Crystallographic and Computational Study on Dexketoprofen Trometamol Dihydrate Salt
}

\author{
Patrizia Rossi ${ }^{1}{ }^{1}$, Paola Paoli $1, * \mathbb{C}$, Stella Milazzo ${ }^{1}$, Laura Chelazzi ${ }^{2} \mathbb{D}$, \\ Maria Paola Giovannoni ${ }^{3}$, Gabriella Guerrini ${ }^{3}{ }^{\circ}$, Andrea Ienco ${ }^{4, *}{ }^{\mathbb{C}}$, Maurizio Valleri ${ }^{5}$ and \\ Luca Conti ${ }^{6}$ (D) \\ 1 Department of Industrial Engineering, University of Florence, via Santa Marta 3, 50139 Florence, Italy; \\ p.rossi@unifi.it (P.R.); stella.milazzo@unifi.it (S.M.) \\ 2 Centro di Cristallografia Strutturale, University of Florence, via della Lastruccia 3, Sesto F.no, \\ 50019 Florence, Italy; laura.chelazzi@unifi.it \\ 3 NEUROFARBA, Sezione Farmaceutica e Nutraceutica, University of Florence, Via Ugo Schiff 6, Sesto F.no, \\ 50019 Florence, Italy; mariapaola.giovannoni@unifi.it (M.P.G.); gabriella.guerrini@unifi.it (G.G.) \\ 4 CNR-ICCOM, via Madonna del Piano 10, Sesto F.no, 50019 Florence, Italy \\ 5 A. Menarini Manufacturing Logistics and Services s.r.l., via R. Pilo 4, 50131 Florence, Italy; \\ mvalleri@menarini.it \\ 6 Department of Chemistry “U. Schiff”, University of Florence, via della Lastruccia 3, Sesto F.no, \\ 50019 Florence, Italy; luca.conti@unifi.it \\ * Correspondence: paola.paoli@unifi.it (P.P.); andrea.ienco@iccom.cnr.it (A.I.)
}

Received: 29 June 2020; Accepted: 30 July 2020; Published: 31 July 2020

check for updates

\begin{abstract}
Dexketoprofen trometamol is the tromethamine salt of dexketoprofen [(2S)-2-(3-benzoylphenyl) propanoic acid-2-amino-2-(hydroxymethyl)propane-1,3-diol], a nonsteroidal anti-inflammatory drug (NSAID) used for the treatment of moderate- to strong-intensity acute pain. The crystal structure of the hitherto sole known hydrate phase of dexketoprofen trometamol (DK-T_2 $\left.\mathbf{H}_{\mathbf{2}} \mathbf{O}\right)$, as determined by single-crystal X-ray diffraction, is presented. The water molecules are arranged in dimers included in isolated sites and sandwiched between piles of trometamol cations. The molecular and crystal structures of DK-T_2 $\mathbf{H}_{\mathbf{2}} \mathbf{O}$ are analyzed and compared to those of the parent anhydrous crystal form DK-T_A. In both the crystal structures, all the potential H-bond donors and acceptor of the dexketoprofen and trometamol ions are engaged, and both the species crystallize in the $\mathrm{P} 2{ }_{1}$ space group. However, during the DK-T_A $\rightarrow$ DK-T_ $\mathbf{2} \mathbf{H}_{\mathbf{2}} \mathbf{O}$ hydration process, the unique symmetry axis is not conserved, i.e., the ions are arranged in a different way with respect to the screw axis, even if the two crystal structures maintain structural blocks of DK anions and T cations. Quantum mechanical solid-state calculations provide some hints for the possible intermediate structure during the crystalline-crystalline hydration/dehydration process.
\end{abstract}

Keywords: dexketoprofen trometamol; hydrates; crystal structure; NSAIDs

\section{Introduction}

Upon crystallization, a large number of active pharmaceutical ingredients (APIs) incorporate solvent molecules into their crystal lattice [1]. The inclusion of solvent molecules in the crystal lattice leads to changes in the unit cell dimensions, content and intermolecular interactions with respect to the pristine compound. As a consequence, the solvate of a drug molecule usually presents different physical, chemical and mechanical properties with respect to its unsolvated species, which obviously has a significant impact on the stability, solubility and performance of the API, as well as on the related regulatory issues. For this phenomenon, i.e., the possibility for a given substance to exist in different crystal forms, with each one having a different elemental composition as a result of the inclusion of 
one or more solvent molecules, several authors have used the terms "pseudopolymorphism" [2] or "solvatomorphism" [3].

The most common type of solvate, where the trapped solvent is water, is called a hydrate [4] which, according to Morris and Rodriguez-Hornedo, can be classified in three categories, depending on how the water molecules are organized into the crystal lattice [5]: (i) channel hydrates; (ii) isolated site hydrates; (iii) metal ion associated hydrates.

Many APIs are able to form hydrates due to the capability of the water molecule to act both as $\mathrm{H}$-bond donor and acceptor and also because water is often present in the manufacturing environment of pharmaceuticals solids. In fact, APIs can be in contact with water during different processing steps (crystallization, lyophilization, wet granulation, aqueous film coating or spray drying) and are exposed to water during storage in an atmosphere containing water vapor. In some cases, water molecules can improve the stability of metastable solid forms. The formation of strong intermolecular hydrogen bonding may improve the stability of the hydrated crystal form compared to the corresponding anhydrate, providing stability to the crystal lattice [6]. The cardiovascular drug creatine phosphate sodium tetrahydrate, the beta-lactam antibiotic ampicillin trihydrate and the synthetic broad-spectrum cephalosporin antibiotic, cephalexin monohydrate are some examples of marketed stable hydrated forms of APIs [7-9]. Finally, various hydrates of the same compound can exhibit different properties. For example, olanzapine has three hydrated polymorphs: dihydrate D, B and E. Dihydrate D is the most thermodynamically stable form and has the most efficient crystal packing and hence the highest density [6].

X-ray crystallography is the key to studying structure-property relationships and single crystal X-ray diffraction (SCXRD) is the method of choice for molecular and crystal structure determination when crystals are available, as well as X-ray powder diffraction (XRPD), which provides an alternative valuable tool for the characterization of crystalline powder materials [10]. Both of these techniques [11-15], complemented by differential scanning calorimetry [16-18], solid state NMR [19], IR-UV and Raman spectroscopy [20-22] and modelling [23-29], can be successfully used to characterize the solid state features and behavior (e.g., phase stability, polymorphism, phase transformation) of a large variety of compounds including APIs' key precursors, well-known APIs as well as new promising active pharmaceutical compounds.

Non-steroidal anti-inflammatory drugs (NSAIDs) represent a widespread class of analgesic medications which are used to reduce pain and inflammation.

Dexketoprofen (Scheme 1 top), i.e., the S-enantiomer of ketoprofen; is usually formulated as 2-amino-2-(hydroxymethyl)-1,3-propanediol (TRIS or trometamol, Scheme 1 bottom) salt which is absorbed rapidly [30].<smiles>C[C@H](C(=O)O)c1cccc(C(=O)c2ccccc2)c1</smiles><smiles>NC(CO)(CO)CO</smiles>

Scheme 1. Schematic drawing of dexketoprofen (top) and trometamol (bottom). 
The anhydrate salt dexketoprofen trometamol, DK-T hereafter, is known to exhibit different crystal forms [31,32]: polymorph A (DK-T_A) and polymorph B (DK-T_B).DK-T_A is the thermodynamically stable crystalline form used to manufacture dosage-form products and its molecular and crystal structures, as obtained from SCXRD, were recently published by several of us [33]. Meanwhile, XRPD measurements allowed researchers to obtain cell parameters, the space group and $Z$ of both the thermodynamically unstable, but kinetically preferred, DK-T_B solid form and the previously unknown dihydrate form DK-T_2 $\mathbf{H}_{2} \mathrm{O}$ [31].

The crystal of DK-T_A belongs to the monoclinic crystal system, $\mathrm{P} 2{ }_{1}$ space group, and four dexketoprofen anions and four trometamol cations are present in the asymmetric unit $\left(1.30 \mathrm{mg} / \mathrm{cm}^{3}\right.$ at rt) as well as the microcrystalline powder of DK-T_2 $\mathbf{H}_{2} \mathbf{O}$. Given that for $\mathrm{P} 2_{1}$, the $\mathrm{Z}$ value is 2 , we reasoned [31] that in the asymmetric unit, two dexketoprofen/trometamol independent pairs and four water molecules should be present $\left(1.29 \mathrm{mg} / \mathrm{cm}^{3}\right.$ at $\left.\mathrm{rt}\right)$.

In that paper, the DK-T_A $\rightarrow$ DK-T_ $\mathbf{2} \mathbf{H}_{\mathbf{2}} \mathbf{O}$ and the reverse transformation were studied: the addition of water drop by drop to $\mathbf{D K T}$ _A, in a DK-T_A/ $\mathbf{H} \mathbf{H}_{\mathbf{2}} \mathbf{O}$ stoichiometric ratio ranging from 1:2 to 1:7, always leads to the dihydrate species. The hydration process is quick, not accompanied by the formation of a detectable amorphous phase and reversible. On these grounds, we speculated that both the anhydrous and hydrate crystal architectures did not suffer upon water uptake/release and that the dihydrate form belongs to the class of the channel hydrates and most probably is a planar hydrate.

Now we present here the molecular and crystal structure of the DK-T_2 $\mathbf{H}_{\mathbf{2}} \mathbf{O}$ as obtained by SCXRD. Until now, no solvates of dexketoprofen trometamol have been described in the literature, so this is the first structural characterization of its hydrate form. Attention has been paid to the role played by the water molecules in the crystal lattice and the hypothesis formulated in our previous study, about the nature of the dihydrate species (planar hydrate) was checked due to the new information acquired. Quantum chemical calculations have been used to study the crystal structure relationships between DK-T_2 $\mathbf{H}_{2} \mathbf{O}$ and the parent anhydrous phase $\mathbf{D K}-\mathbf{T} \_\mathbf{A}$.

\section{Materials and Methods}

Dexketoprofen trometamol (DK-T) was kindly supplied by the Menarini Group. This sample contains the A polymorph of dexketoprofen trometamol (DK-T_A), as provided by a comparison of its most significant XRPD peaks and those listed in the EP1739072A1 PATENT for form A. It was used as received without further purification.

\subsection{Procedures of DK-T_A Hydration and DK-T_2 $\mathrm{H}_{2} \mathrm{O}$ Crystallization}

The hydration process of the microcrystalline powder of DK-T_A was followed under a Linkam Hot-stage microscope by using different DK-T: $\mathrm{H}_{2} \mathrm{O}$ molar ratios (1:2 and 1:10).

Crystals of DK-T_2 $\mathbf{H}_{2} \mathrm{O}$ (vide infra) suitable for single crystal X-ray diffraction were obtained by adding 20 equiv of $\mathrm{mQ}$ water drop by drop to DK-T_A form. The mixture was stirred until the complete dissolution of the powder. The resulting clear solution was kept at ambient conditions. After one week, by the slow evaporation of the solvent, plate-shaped, colorless crystals formed.

\subsection{X-ray Powder Diffraction (XRPD)}

XRPD patterns were measured in air at ambient temperature on a Bruker New D8 Da Vinci diffractometer equipped with a Bruker LYNXEYE-XE detector. Data over the range $3^{\circ}-60^{\circ} 2 \theta$ were collected with $0.02^{\circ}$ increments of $2 \theta$, and a counting time of $1 \mathrm{~s} /$ step. The copper $(\mathrm{Cu}-\mathrm{K} \alpha)$ radiation $(\lambda=1.54056 \AA)$ was used and the tube voltage and current were set to $40 \mathrm{kV}$ and $40 \mathrm{~mA}$, respectively.

\subsection{Single Crystal X-Ray Data Collection and Structure Solution}

Single crystal X-ray diffraction data of DK-T_ $2 \mathbf{2 H}_{\mathbf{2}} \mathbf{O}$ were collected at $100 \mathrm{~K}$ using $\mathrm{Cu}-\mathrm{K} \alpha$ radiation $(\lambda=1.54178 \AA$ A $)$ on a Bruker Apex-II CCD diffractometer (Bruker Corporation, Billerica, MA, USA). Data were collected with the Bruker APEX2 program [34] and integrated and reduced with the Bruker SAINT 
software [35]. Dexketoprofen trometamol dihydrate crystallizes in the monoclinic crystal system, space group $P 2_{1}$. The structure was solved using the SIR-2004 package [36] and was refined on $\mathrm{F}^{2}$ by the full-matrix least-squares technique using the SHELXL-2018/3 [37] program package. All non-hydrogen atoms were refined with anisotropic displacement parameters. The $\mathrm{H}$ atoms, bonded to oxygen atoms, were found in the Fourier density maps and their coordinates were freely refined, while their thermal parameter was set in agreement with the atom to which they are bonded. In order to avoid unrealistic O-H bond distances, DFIX and DANG restraints were used for the water molecules. All the other hydrogen atoms were set in a calculated position. Geometrical calculations were performed by PARST97 [38], and molecular plots were produced by the programs ORTEP-3 [39], Mercury [40] and Discovery Studio 2019 Client [41].

Table 1 lists crystal data and refinement parameters of DK-T_2 $\mathbf{2 H}_{\mathbf{2}} \mathbf{O}$. Structural data can be obtained free of charge from The Cambridge Crystallographic Data Centre CCDC deposition number 2012545.

Table 1. Crystallographic data and refinement parameters for the dihydrate phase of dexketoprofen trometamol (DK-T_2 $\left.\mathbf{H}_{2} \mathrm{O}\right)$.

\begin{tabular}{|c|c|}
\hline & DK-T_2 $\mathrm{H}_{2} \mathrm{O}$ \\
\hline Formula & {$\left[\mathrm{C}_{4} \mathrm{H}_{12} \mathrm{NO}_{3}\right]^{+}\left[\mathrm{C}_{16} \mathrm{H}_{13} \mathrm{O}_{3}\right]^{-} \cdot 2 \mathrm{H}_{2} \mathrm{O}$} \\
\hline MW & 411.44 \\
\hline $\mathrm{T}(\mathrm{K})$ & 100 \\
\hline$\lambda(\AA)$ & 1.54178 \\
\hline Crystal system, space group & $\begin{array}{c}\text { Monoclinic, } P 2_{1} \\
\mathrm{a}=8.480(4)\end{array}$ \\
\hline Unit cell dimensions $\left(\AA,^{\circ}\right)$ & $\begin{array}{c}\mathrm{b}=27.7440(10) ; \beta=90.479(3) \\
\mathrm{c}=8.7770(4)\end{array}$ \\
\hline Volume $\left(\AA^{3}\right)$ & $2064.89(15)$ \\
\hline $\mathrm{Z}, \mathrm{D}_{\mathrm{c}}\left(\mathrm{mg} / \mathrm{cm}^{3}\right)$ & $4,1.323$ \\
\hline$\mu\left(\mathrm{mm}^{-1}\right)$ & 0.857 \\
\hline $\mathrm{R}_{1}[\mathrm{I}>2 \sigma(\mathrm{I})]$ & 0.0639 \\
\hline wR2 (all) & 0.1672 \\
\hline GOFs (Goodness of fit) & 1.041 \\
\hline
\end{tabular}

\subsection{Computational Methods}

The crystal-packing arrangement was analyzed with Mercury [38]. Crystal-Explorer17 [42] was used to compute the Hirshfeld surfaces (HS) and their associated 2D fingerprint plots to investigate the intermolecular interactions in the crystal packing of $\mathbf{D K}-\mathbf{T} \_2 \mathbf{H}_{\mathbf{2}} \mathbf{O}$.

The CRYSTAL17 software package (Colleretto Giacosa (Turin), Italy) [43] has been used for the optimized geometries and energetics calculated at the HF-3c level of theory [44,45]—further details are given in Supplementary Materials. Table S1 reports the optimized coordinates for DK-T_2H2Oc, DK-T_Ac, and DK-T_C (vide infra).

\section{Results and Discussion}

\subsection{Procedures of DK-T_A Hydration and DK-T_2 $\mathrm{H}_{2} \mathrm{O}$ Crystallization}

In order to get insights into the anhydrous (DK-T_A)-hydrate (DK-T_2 $\left.\mathbf{H}_{\mathbf{2}} \mathbf{O}\right)$ transformation, we follow the hydration process under microscope.

When a 1:2 DK-T: $\mathrm{H}_{2} \mathrm{O}$ molar ratio mixture was used, no visible changes take place, as provided by the photos reported in Figure S1; the XRPD pattern collected after 1 minute from the mixing shows that the hydrate form was formed (Figure S2, Supplementary Materials). This observation further strengthens the hypothesis that in these experimental conditions, the hydration process takes place through a crystalline-crystalline phase transformation. By contrast, a 1:10 DK-T: $\mathrm{H}_{2} \mathrm{O}$ molar ratio mixture causes a dissolution of the starting material followed by a fast recrystallization of the DK-T_2 $\mathbf{H}_{\mathbf{2}} \mathbf{O}$ form (Figure 1). The same experiment, monitored via XRPD, shows that just after the mixing, the interconversion of anhydrous-hydrate was completed (Figure S3, Supplementary Material). 

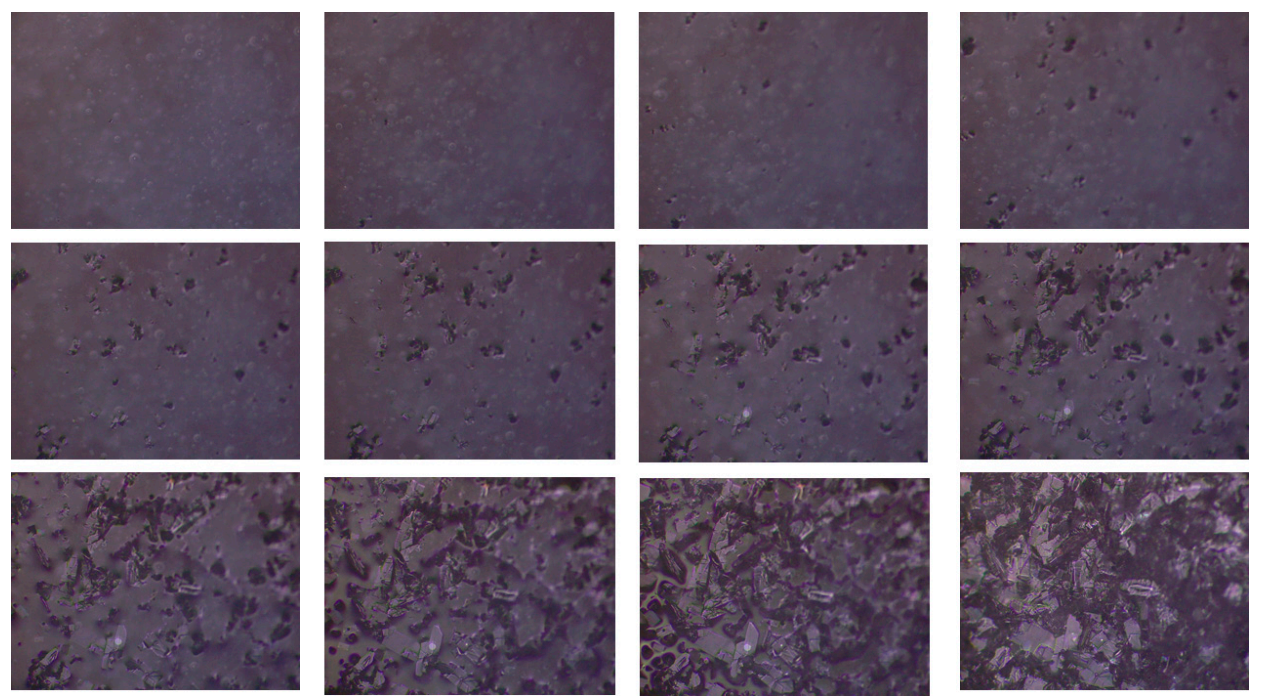

Figure 1. From left top to right bottom: photos taken every $20^{\prime \prime}$ showing the fast recrystallization when a 1:10 DK-T: $\mathrm{H}_{2} \mathrm{O}$ molar ratio mixture was used.

Finally, the addition of high amount of water (20 equiv) to DK-T_A led to the formation of single crystals. SCXRD analysis (vide infra) reveals that crystals belong to the same crystalline phase of the microcrystalline powder already characterized (DK-T_2 $\left.\mathbf{H}_{\mathbf{2}} \mathbf{O}\right)$. Crystals of DK-T_2 $\mathbf{H}_{\mathbf{2}} \mathbf{O}$ are stable at least for a time period of six months at ambient conditions ( $293 \mathrm{~K}$ and $\sim 60 \% \mathrm{RH})$.

\subsection{Molecular and Crystal Structure from Single-Crystal X-Ray Diffraction}

The crystalline phase of DK-T_ $\mathbf{2} \mathbf{H}_{\mathbf{2}} \mathbf{O}$, as determined by SCXRD, and that of the microcrystalline sample of the dihydrate dexketoprofen trometamol reported in ref. [31], are identical, as provided by comparing calculated (Figure S4 Supplementary Materials) and measured powder diffraction patterns (see ref. [31]). In the asymmetric unit of DK-T_2 $\mathbf{H}_{\mathbf{2}} \mathbf{O}\left(\mathrm{P2}_{1}\right.$ space group), there are two dexketoprofen/trometamol independent pairs and four water molecules (Figure 2). An ORTEP drawing of the $a$ independent dexketoprofen trometamol pair together with the atom labelling is shown in Figure 3. The overall shape of the two independent dexketoprofen anions, DK hereafter, (labelled in the following as $a$ and $b$ ) is very similar, as provided by the sequence of the $\tau_{1}-\tau_{3}$ dihedral angles (see Table 2), which can be described as (ap)-(sp)-(-sc) [46]. The conformational isomer of the dihydrate species is almost identical to that labelled as $c$ in the crystal structure of the parent anhydrous species (see Figure 4) which, from a relaxed potential energy surface scan of about $\tau 1$, resulted in the highest energy ( $\Delta \mathrm{E}$ about $1 \mathrm{kcal} / \mathrm{mol}$, [31]). Finally, a search in the Cambridge Structural Database (version 5.41) [47] shows that $\tau_{1}-\tau_{3}$ values are within the populated ranges (see Figure S5 in Supplementary Materials).

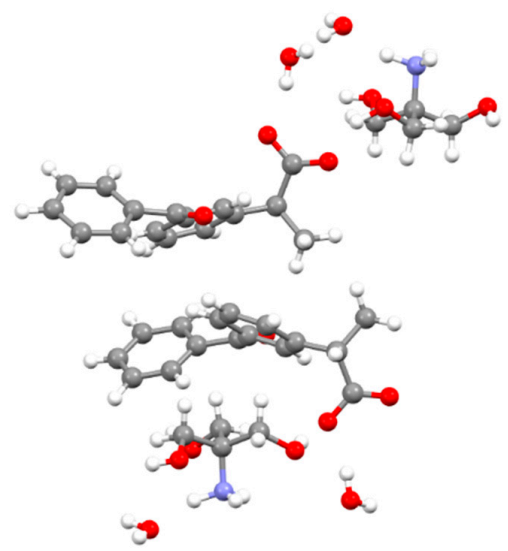

Figure 2. View of the asymmetric unit of DK-T_2 $\mathbf{H}_{2} \mathrm{O}$. 

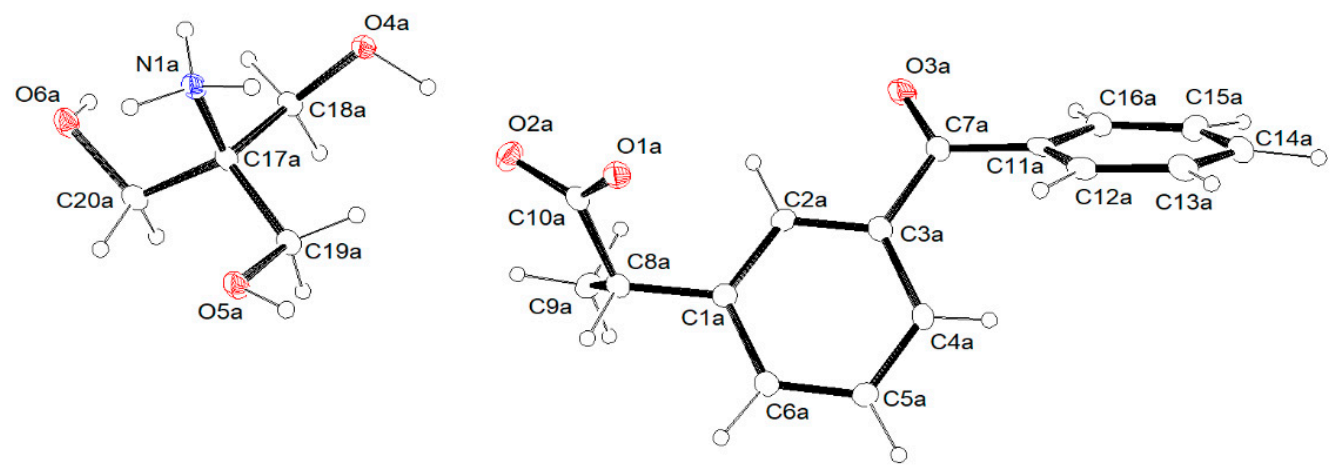

Figure 3. ORTEP-3 view of the $a$ independent dexketoprofen trometamol pair in DK-T_2 $\mathbf{H}_{\mathbf{2}} \mathbf{O}$ with atoms labelling (ellipsoid probability $=25 \%$ ).

Table 2. Selected dihedral angles for DK-T_2 $\mathbf{H}_{2} \mathbf{O}$ as obtained from single crystal X-ray diffraction.
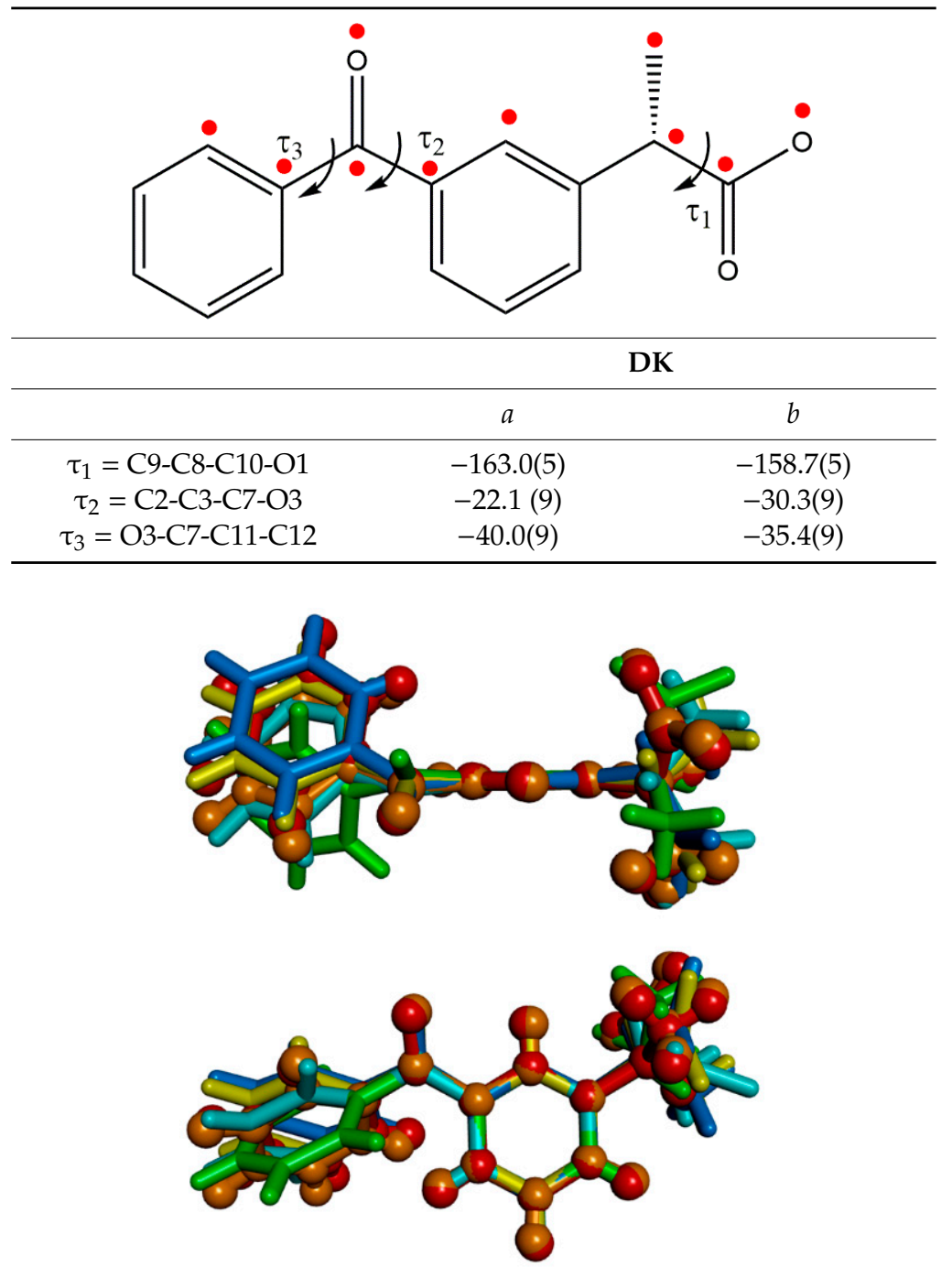

Figure 4. Superimposition (by using the C1-C6 ring) of the molecular structures of the DK anions as found in the anhydrous (stick; 4 independent DKs: $A=$ green; $b=$ blue; $c=$ pale blue; $d=$ yellow) and hydrate (ball and stick; 2 independent DKs: $\mathrm{A}=$ orange; $\mathrm{b}=$ red) phases of the trometamol salt.

The two trometamol cations, T hereafter (labelled in the following as $a$ and $b$ ), which are well superimposable, adopt the quite usual $(+s c)(+s c)(+s c)$ conformation (see Table S2). 
The crystal lattice of DK-T_2 $\mathbf{H}_{\mathbf{2}} \mathbf{O}$ is held together by a hydrogen bond network involving all the potential H-bond donor and acceptor sites of dexketoprofen and water molecules (Table 3). In particular, the carboxylate oxygen atoms (O1 and $\mathrm{O} 2)$ of each dexketoprofen anion interact with two -OH groups provided by two trometamol cations and two water molecules, whereas the ammonium group of each trometamol cation is H-bonded to one water molecule $(\mathrm{O} 1 \mathrm{~W})$ and to two hydroxyl oxygen atoms provided by different trometamol cations. As a result of these latter interactions, alternating $a / b$ trometamol cations bound through $\mathrm{NH}_{3} \cdots \mathrm{OH}$ strong hydrogen bonds $\left(R_{2}^{2}(10)\right.$ motif [48], Table 3) pile along the c-axis direction (Figure 5 top). In addition, each trometamol bound water molecule (O1W, represented in a space-filling style in Figure 5 middle) acts, in turn, as a H-bond donor towards the oxygen of a DK carboxylate group (O1) and of a symmetry-independent water molecule (O2W, see Figure 5 bottom). Thus, each O1W water molecule bridges a dexketoprofen/trometamol pair and, at the same time, gives rise to water-water dimers, being involved in three H-bonds. By contrast, the $\mathrm{O} 2 \mathrm{~W}$ water molecules are involved in four hydrogen bonds: as $\mathrm{H}$-bond donor towards the oxygen atoms provided by the DK carboxylate and the Thydroxyl groups and as $\mathrm{H}$-bond acceptor towards $\mathrm{O} 1 \mathrm{~W}$ and the hydroxyl group of a further trometamol cation.

It is noteworthy, as already pointed out [31], that the insertion of the water molecules does not significantly contribute to fill void spaces in DK-T_A (no empty space was detected in the crystal lattice of the anhydrous form by the Voids routine of Mercury [38] and, accordingly, crystal densities $\left(1.323\right.$ and $\left.1.329 \mathrm{mg} / \mathrm{cm}^{3}\right)$ and packing indexes (0.70 for both structures [49]) are almost identical), nor involve additional potential H-bond sites with respect to the anhydrous phase.

Table 3. Selected H-bonds in DKT_2 $\mathbf{H}_{2} \mathbf{O}$.

\begin{tabular}{|c|c|c|c|}
\hline & $\begin{array}{c}X \cdots Y(\AA), H^{\cdots} \cdots Y(\AA) \\
X-H \cdots Y\left({ }^{\circ}\right)\end{array}$ & & $\begin{array}{c}X \cdots Y(\AA), H^{\cdots}{ }^{\prime} Y(\AA) \\
X-H \cdots Y\left(^{\circ}\right)\end{array}$ \\
\hline \multicolumn{4}{|l|}{ Strongest donor } \\
\hline N1A-H1N1 ... O1WA & $2.784(7) / 2.020(4) / 140.6(3)$ & & \\
\hline N1A-H1N2 .. O5B ${ }^{1}$ & $2.749(6) / 1.933(4) / 148.3(3)$ & & \\
\hline \multirow[t]{2}{*}{ N1A-H1N3 ... O6B } & $2.883(6) / 2.095(4) / 144.3(3)$ & & \\
\hline & & Water... Water & \\
\hline N1B-H1N6 ... O1WB & $2.787(7) / 2.034(4) / 139.2(3)$ & $\begin{array}{c}\text { O1WA-H1W2 ... } \\
\text { O2WA }\end{array}$ & $2.801(6) / 1.93(6) / 171(5)$ \\
\hline N1B-H1N5 ... O4A & $2.757(6) / 1.953(4) / 146.4(3)$ & O1WB-H1W3 ... O2WB 3 & $2.825(6) / 1.98(6) / 163(5)$ \\
\hline N1B-H1N4 ... O5A ${ }^{3}$ & $2.880(6) / 2.096(4) / 143.6(3)$ & & \\
\hline Strongest acceptor & & $\begin{array}{l}\text { Water (acceptor) ... } \\
\text { trometamol (donor) }\end{array}$ & \\
\hline O1A ... H6OA-O6A ${ }^{4}$ & $2.711(6) / 2.04(8) / 161(9)$ & O2WA ... H6OB-O6B & $2.786(6) / 1.94(8) / 177(8)$ \\
\hline $\mathrm{O} 2 \mathrm{~A} \ldots \mathrm{H} 4 \mathrm{OA}-\mathrm{O} 4 \mathrm{~A}^{5}$ & $2.586(6) / 1.65(7) / 153(6)$ & $\mathrm{O} 2 \mathrm{WB} \ldots \mathrm{H} 5 \mathrm{OA}-\mathrm{O} 5 \mathrm{~A}^{2}$ & $2.779(6) / 1.91(8) / 169(8)$ \\
\hline O1A ... H1W4-O1WB ${ }^{4}$ & $2.903(6) / 2.01(5) / 174(4)$ & & \\
\hline \multirow[t]{2}{*}{$\mathrm{O} 1 \mathrm{~A} \ldots \mathrm{H} 2 \mathrm{~W} 1-\mathrm{O} 2 \mathrm{WA}^{4}$} & $2.717(6) / 1.85(4) / 170(3)$ & & \\
\hline & & $\begin{array}{c}\text { Water (donor) ... } \\
\text { trometamol (acceptor) }\end{array}$ & \\
\hline O1B ... H4OB-O4B 3 & $2.708(6) / 2.01(8) / 167(9)$ & O2WA-H2W2 .. O $4 \mathrm{~B}^{7}$ & $2.817(6) / 1.96(6) / 175(6)$ \\
\hline O2B ... H5OB-O5B 6 & $2.588(6) / 1.76(8) / 174(8)$ & O2WB-H2W4 ... O6A & $2.811(6) / 1.94(6) / 172(5)$ \\
\hline O1B ... H1W1-O1WA & $2.884(6) / 2.00(5) / 173(4)$ & & \\
\hline $\mathrm{O} 1 \mathrm{~B} \ldots \mathrm{H} 2 \mathrm{~W} 3-\mathrm{O} 2 \mathrm{WB}^{7}$ & $2.728(6) / 1.86(4) / 164(3)$ & & \\
\hline
\end{tabular}




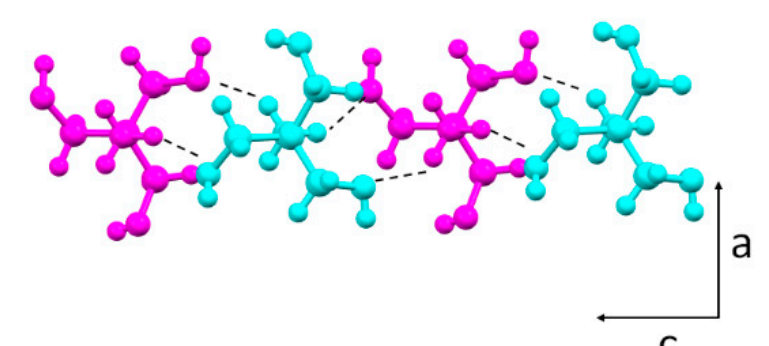

C

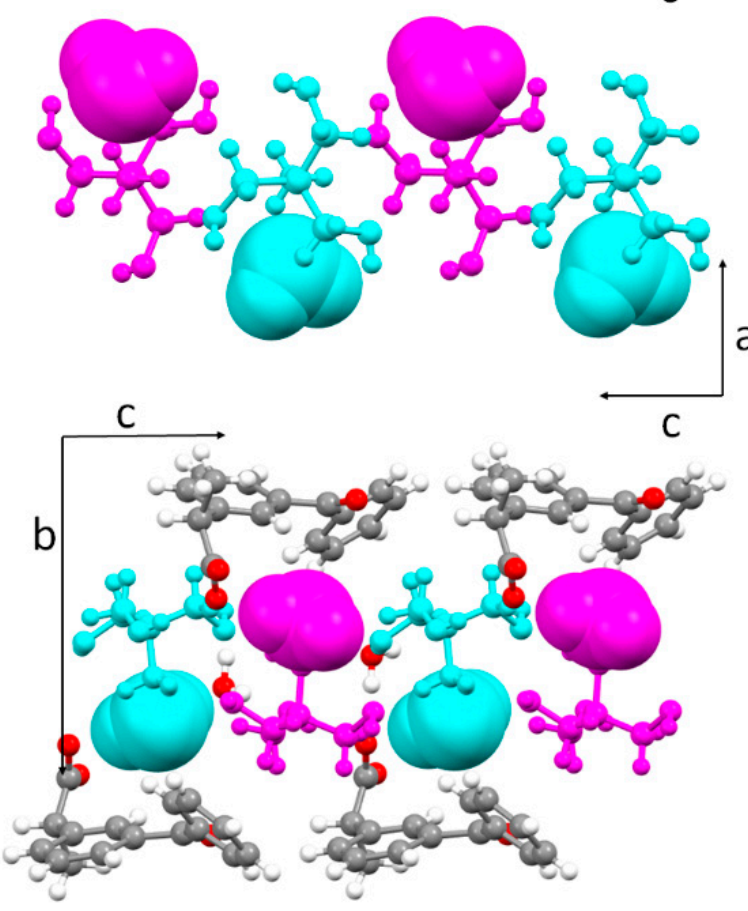

Figure 5. View of the crystal packing of DK-T_2 $\mathbf{H}_{\mathbf{2}} \mathrm{O}$ (for the sake of clarity only selected DK, $\mathbf{T}$ and water molecules are shown). (top) $a-b-a-b$ sequence of trometamol cations interacting via H-bonds, viewed along the $\mathrm{b}$ axis direction); (middle) $\mathrm{H}$-bonded trometamol-water molecules (space-filling style, magenta O1WA, cyan O1WB); (bottom) selected H-bond interactions involving DK, T and water molecules (see text), viewed along the a axis direction.

Figure 6 shows an overall picture of the DK-T_2 $\mathbf{2} \mathbf{H}_{\mathbf{2}} \mathbf{O}$ crystal packing (top): the crystallization water molecules, organized in dimers, are sandwiched between stacks of $\mathrm{H}$-bonded trometamol cations aligned along the $\mathrm{c}$ axis direction (left). The DK anions (those labelled as $a$ are interacting each other via $\mathrm{C}-\mathrm{H} \cdots \mathrm{O}=\mathrm{C}$ interactions) are disposed in a double layer between the T's parallel chains. As a result, the structure is made of alternating structural blocks of DK anions and T cations (right) and in this respect resembles that of the parent anhydrous species (DK-T_A, Figure 7 bottom), notwithstanding the different relative arrangement of the trometamol piles and the dexketoprofen anions. So, as it is evident by comparing the pictures in Figure 7, during the DK-T_A $\rightarrow$ DK-T_ $2 \mathbf{2 H}_{\mathbf{2}} \mathbf{O}$ crystal transformation (and the reverse one), the unique symmetry axis is not conserved, with DK and T ions being arranged in a different way with respect to the screw axis.

A recent work of Werner and Swift found more than 2000 pairs of hydrate and anhydrous species [50] in the Cambridge Structural Database [45]. Using their refcode list, we found 281 pairs with at least one of the structures with $P 2_{1}$ symmetry. Only 48 pairs $(17.1 \%)$ have $P 2_{1}$ as the space group for both the hydrate and anhydrous species (Table S3 in Supplementary Materials). For comparison, in the whole dataset, the same space group is maintained in $29.5 \%$ of the cases, while for the $P 2_{1} 2_{1} 2_{1}$ space group, which is another very frequent space group for molecules having a chiral center, the percentage is $24.8 \%$. Interestingly, in the hydrate/anhydrous $P 2_{1} / P 2_{1}$ subset the $\mathrm{Z}$ value is the same in both the species in only 29 cases, while for 10 pairs, the hydrate species have a larger value for $Z$, and the opposite holds for the remaining 9 pairs. 
From a visual analysis of the 48 hydrate/anhydrous pairs, we found that in only 24 cases, the overall molecular packing is comparable between the hydrate and anhydrous crystals and the water molecules do not disrupt the molecular arrangements of the organic crystals too much. In other words, for the $P 2_{1}$ space group, there is a $50 \%$ chance to have closely related hydrate anhydrous structures, and in most cases, they can be described as a dehydrated hydrate or isomorphic hydrate. The DK-T_A $\rightarrow$ DK-T_2 $\mathbf{H}_{\mathbf{2}} \mathbf{O}$ crystal transformation instead belongs to the other group: there are no relationships between the screw axes in the two crystals.

As mentioned above, the water molecules are arranged in dimers connected through a carboxylic oxygen atom (O1) and describe as a whole a zig-zag motif extending along the $c$ axis direction (Figure 6 top). In fact, each water dimer is hosted in an isolated site, i.e., it is not connected by a channel, as depicted in Figure 7, which shows the voids left following the in silico removal of the crystallization water molecules. In this respect, DK-T_2H2O could be described as isolated site hydrate (with two water molecules in each site); however, the dihydrate species could be also classified as a planar hydrate (a subclass of channel hydrates [51]), given that water molecules are interposed between stacks of Ts (Figure 7 bottom).

Given that the water molecules are sandwiched between columns of trometamol cations parallel to the $\mathrm{c}$ axis direction, it should be expected that the hydration/dehydration process occurs along the $c$ axis. As shown in Figure 6, the organization in alternating structural blocks of DK anions and $\mathrm{T}$ cations is retained in the two crystal forms; however, the unique symmetry axis is not conserved (DK and $\mathrm{T}$ ions arrange differently with respect to the screw axis in the two solid forms). On the other hand, although several attempts made, no trace of the amorphous phase in the XRPD (X-ray Powder Diffraction) (hydration) and VT-XRPD (Variable Temperature XRPD) (dehydration) patterns was detected [31].
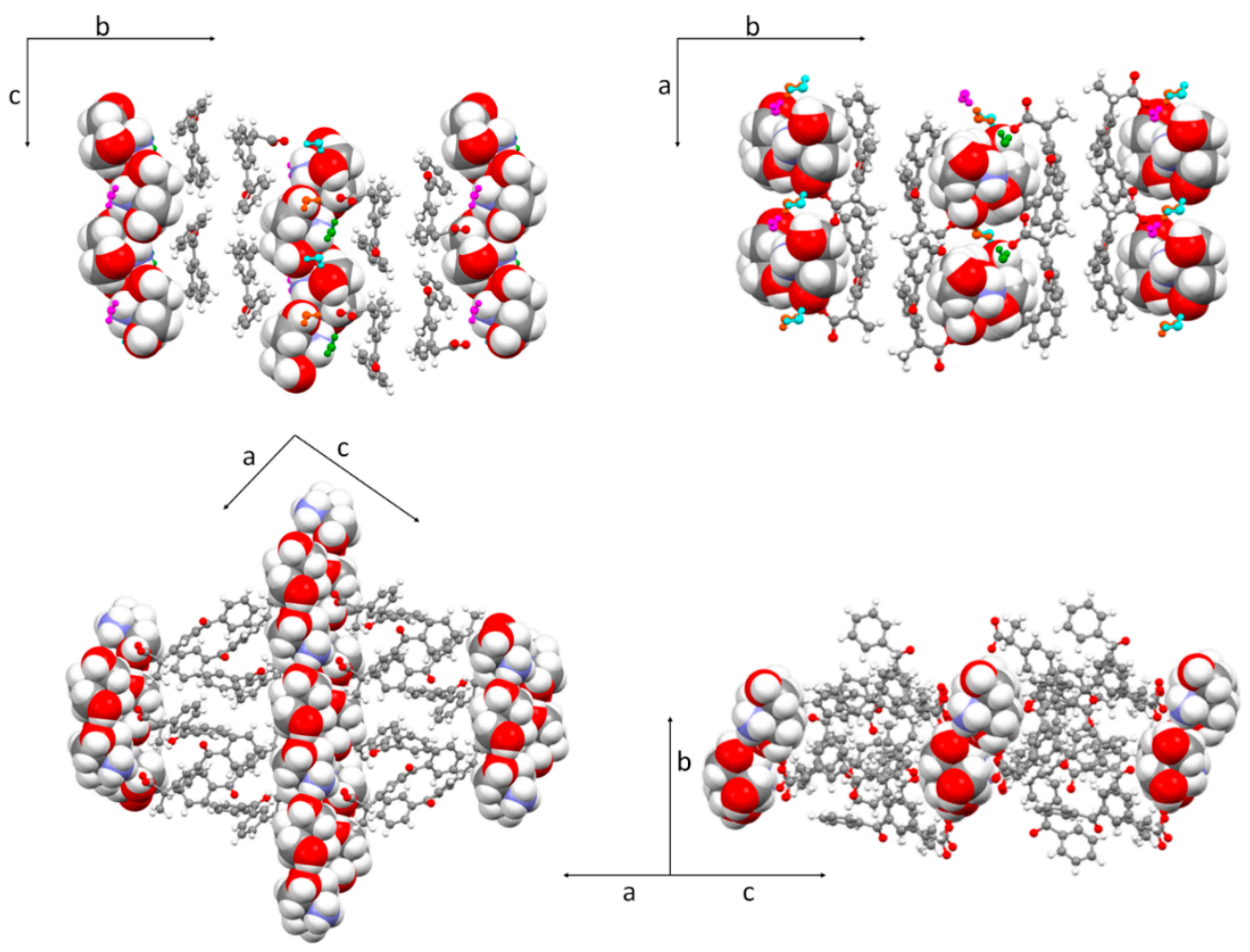

Figure 6. Views of the crystal packing of: DK-T_2 $\mathbf{H}_{\mathbf{2}} \mathbf{O}$ (top) along the a (left) and c (right) axis directions showing the H-bond interactions.; DK-T_A (bottom) along the $b$ axis direction (left) and the $a c$ plane bisector (right). For the sake of clarity, DKs and the water molecules (colored according to the symmetry equivalence) are shown as balls and sticks, and Ts with a space-filling style. 

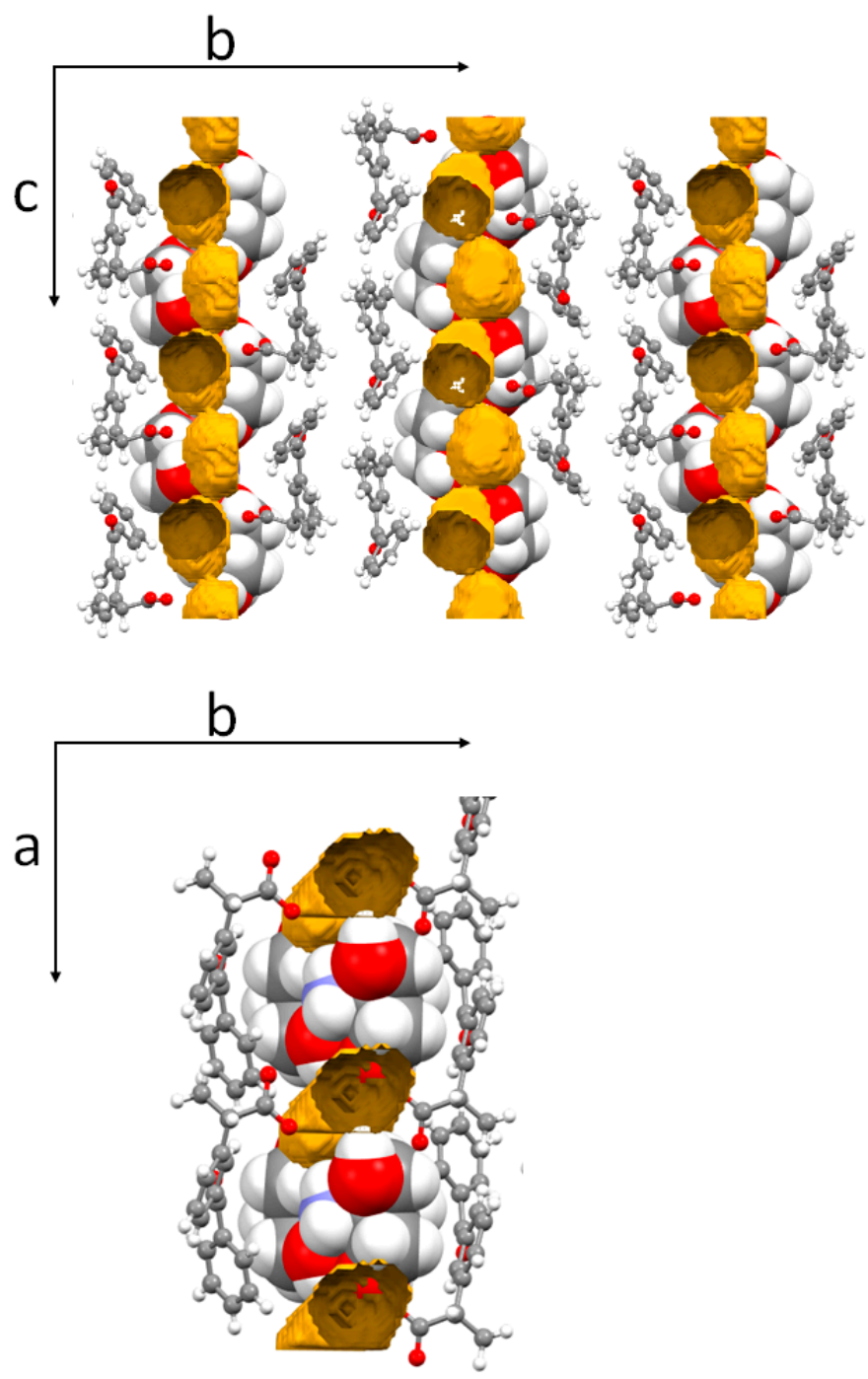

Figure 7. Space occupied by the water molecules in the crystal packing of DK-T__2 $\mathbf{H}_{\mathbf{2}} \mathbf{O}$ along the a (top) and c (bottom) axis directions mapped with the Voids routine in Mercury [38] by using a probe radius of $1.2 \AA$. DKs are shown as ball and stick and Ts with a space-filling style.

\subsection{Crystal Structure from Computational Methods}

As already said, there are no differences in the nature (type, number and geometry) of the $\mathrm{H}$-bond interactions involving each of the two independent dexketoprofen and trometamol ions (Table 2), as well evidenced by the corresponding Hirshfeld surfaces (HSs), the related fingerprint plots (Figures S6 and S7 in Supplementary Materials) and relative contributions to the HS area (Figure S8 in Supplementary Materials). By contrast, the different coordination numbers (3 vs. 4) which characterize the water molecules (O1W vs. O2W) are well evidenced in the corresponding HSs (three red spots vs. four red spots) and in the related fingerprint plots (Figure 8): the bottom right wing comprised between the two spikes which contributes to account for the $\mathrm{H}^{\cdots} \mathrm{H}$ contribution to the HSs area (ca. $51 \%$ for O1W vs. $44 \%$ in $\mathrm{O} 2 \mathrm{~W}$ ). We speculated that the higher $\mathrm{HH}$ contribution for O1W could be a hint of the higher steric hindrance experienced by $\mathrm{O} 1 \mathrm{~W}$, which could be the reason of a three-coordinate geometry, instead of the four-tetrahedral one.

Finally, as for the $\mathrm{O} \cdots$ H interactions, there are no significant differences in terms of HSs, fingerprint plots and related contribution to the HSs area of the DK and T ions in the anhydrous (Figure S9 in Supplementary Materials) and hydrate phases, which agrees well with the observation that in both the crystal structures, all the potential H-bond donors and acceptor are engaged. 

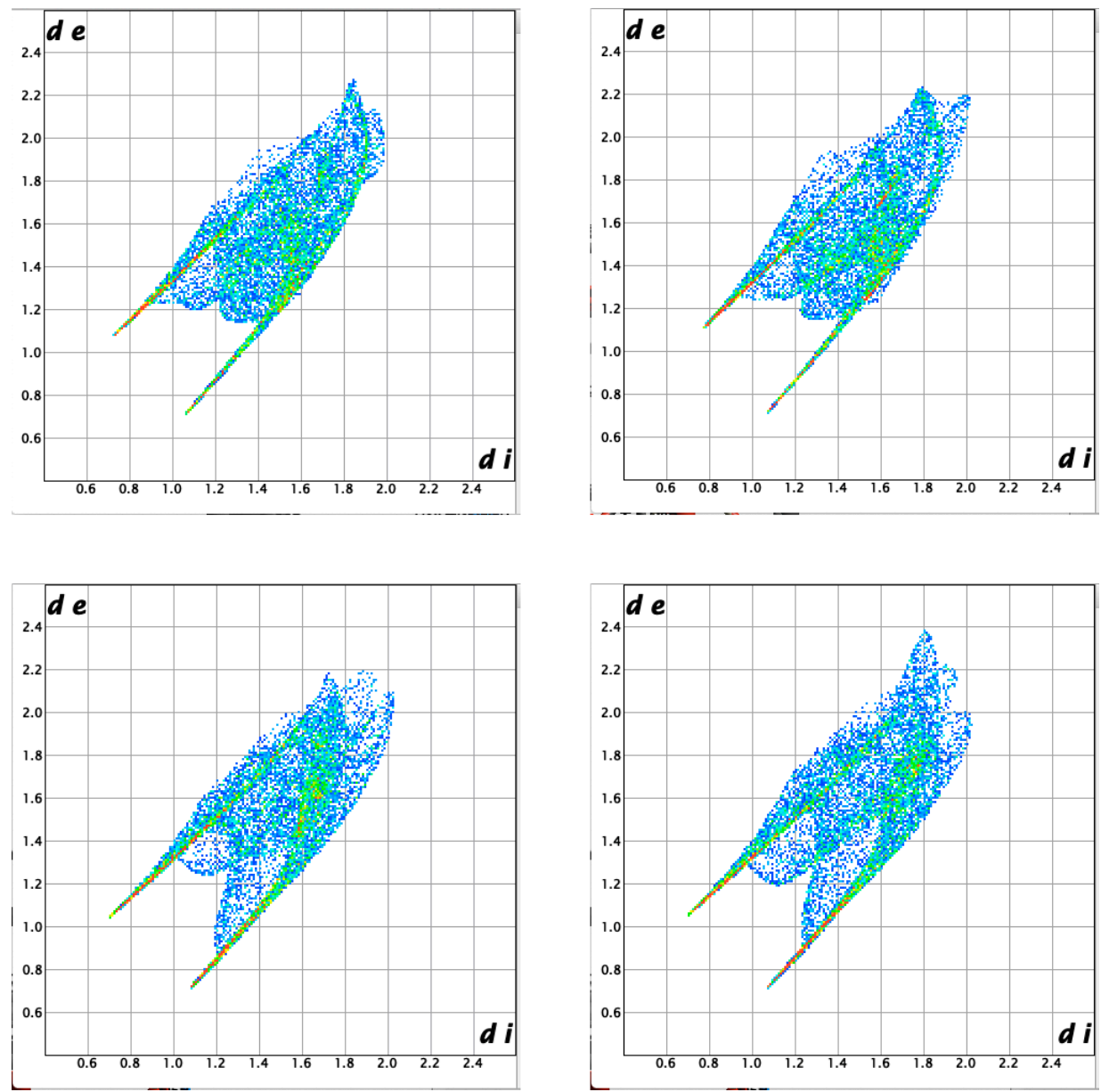

Figure 8. Fingerprint plots of the crystallization water molecules in DK-T_2 $\mathbf{H}_{\mathbf{2}} \mathbf{O}$ : O1WA (top left), O1WB (top right), O2WA (bottom left) and O2WB (bottom right).

We also searched for some hints on the relative arrangements of the trometamol piles in DK-T_2 $\mathrm{H}_{2} \mathrm{O}$ and DK-T_A using quantum mechanical solid-state calculations. First of all, starting from the experimental structures, we optimized DK-T_2 $\mathbf{H}_{\mathbf{2}} \mathbf{O}$ and DK-T_A (DK-T_2 $\mathbf{H}_{\mathbf{2}} \mathbf{O}$ c and DK_TAc, hereafter) in order to verify the adequacy of the theoretical method used. The calculated and experimental volumes differ of about $7.4 \%$ and $4.6 \%$ for DK-T_ $2 \mathbf{H}_{\mathbf{2}} \mathbf{O}$ and DK-T_A, respectively. Tables S4 and S5 in Supplementary Materials show a comparison between the experimental and calculated cell parameters. These differences are in line with the state of the art, also considering that the structures were obtained at $100 \mathrm{~K}$, while the calculations refer to a temperature of $0 \mathrm{~K}$. A better agreement could be obtained using the quasi-harmonic approximation method that allows us to obtain the variations of the cell parameters with the temperature, but it was outside the goal of our work. In any case, looking at the key dihedral angles for DK and T (see Tables S6 and S7 in the Supplementary Materials), we found a difference no larger than $8^{\circ}$, and this ensures that the main orientations of the molecules have been simulated correctly. After that, we removed the water molecules from the optimized DK-T_2 $\mathbf{H}_{\mathbf{2}} \mathbf{O} \mathbf{O c}$ crystal structure and we optimized a dehydrated structure (DK-T_C). The DK-T_C volume is $69.8 \AA^{3}$ (3.7\%) smaller than the volume of the calculated dihydrate structure (DK-T_2 $\mathbf{H}_{\mathbf{2}} \mathbf{O} \mathbf{O c}$ ). As shown by Figure S10 and in comparison with Figure 6, its overall packing is closely related to that found in DK-T_2 $\mathbf{H}_{2} \mathbf{O}$ and the trometamol piles are still present, being the carboxylic groups of DK able to maintain the piles separated.

The DK and T conformations in DK-T_C are still very similar to those observed in DK-T_2 $\mathbf{H}_{\mathbf{2}} \mathbf{O}$ c; nevertheless, several key angles differ by more than $10^{\circ}$, indicating some level of rearrangement of the molecules in the crystal (see Table S6 in the Supplementary Materials). The energy difference between 
DK-T_C and the optimized DK-T_A (DK-T_Ac) is not meaningful, the difference less being than $1 \mathrm{kcal} / \mathrm{mol}$. On the other hand, DK-T_Ac has a larger density than DK-T_C (1.392 vs. $1.352 \mathrm{~g} / \mathrm{cm}^{3}$, respectively) and this can be one of the reasons for the preference of the anhydrous form DK-T_Ac. Then, keeping in mind that no amorphous phases were detected in the transformation of the DK-T salts, the structurally strict similarity between the DK-T_C and DK-T_2 $\mathbf{H}_{\mathbf{2}} \mathbf{O}$ forms may suggest, as a hypothesis, the existence of an intermediate form during the crystalline-crystalline hydration/dehydration process.

\section{Conclusions}

We have reported here the molecular and crystal structures of the dihydrate phase of the dexketoprofen trometamol salt (DK-T_2 $\left.\mathbf{H}_{\mathbf{2}} \mathbf{O}\right)$ as determined by single crystal X-ray diffraction. Diffraction data show that, as in the parent anhydrous phase (DK-T_A), all the potential donor/acceptor sites are involved in the intermolecular H-bond. However, in DK-T_2 $\mathbf{H}_{\mathbf{2}} \mathbf{O}$, at variance with the anhydrous species, the $\mathrm{H}$-bond between the strongest donor/acceptor groups $\left(-\mathrm{NH}_{3}{ }^{+} / \mathrm{COO}^{-}\right)$is mediated by the water molecules. The latter are arranged in isolated dimers extending along the $\mathrm{c}$ axis direction sandwiched between piles of trometamol cations; as a consequence, the classification of the hydrate, isolated hydrate vs. planar hydrate, is not straightforward.

The hydration/dehydration process (and the reverse one) occurs without a change in the space group; however, the unique symmetry axis is not conserved, being the DK and T ions arranged in a different way with respect to the screw axis in the two solid forms. Finally, quantum mechanical solid-state calculations provided some hints for the possible intermediate during the crystalline-crystalline hydration/dehydration process.

Supplementary Materials: The following are available online at http://www.mdpi.com/2073-4352/10/8/659/s1, XRPD patterns, Hirshfeld surfaces and related fingerprint plots, comparison between experimental and calculated data tables.

Author Contributions: Conceptualization, P.P., P.R. and A.I.; methodology, L.C. (Luca Conti), M.P.G., G.G. and S.M.; software, A.I.; investigation, P.R., L.C. (Laura Chelazzi) and M.V.; data curation, P.P. and P.R.; writing-original draft preparation, P.P., P.R., A.I. and S.M.; writing-review and editing, P.P., P.R. and S.M.; supervision, P.P. and A.I. All authors have read and agreed to the published version of the manuscript.

Funding: M.P.G.: G.G., P.P., P.R., and S.M. thank the Fondazione Cassa di Risparmio di Firenze (project 2018.0980).

Acknowledgments: Authors thank the Centro di Cristallografia Strutturale (CRIST) of the University of Florence for the X-ray diffraction facilities and Samuele Ciattini for his valuable technical assistance.

Conflicts of Interest: The authors declare no conflict of interest.

\section{References}

1. Byrn, S.R.; Zografi, G.; Chen, X.S. Solid-State Properties of Pharmaceutical Materials, 1st ed.; John Wiley \& Sons: New York, NY, USA, 2017; pp. 38-39.

2. Nangia, A. Pseudopolymorph: Retain This Widely Accepted Term. Cryst. Growth Des. 2006, 6, 2-4. [CrossRef]

3. Brittain, H.G. Theory and principles of polymorphic systems. In Polymorphism in Pharmaceutical Solids; Brittain, H.G., Ed.; Marcel Dekker Inc.: New York, NY, USA, 1999; pp. 1-33.

4. Aaltonen, J.; Allesø, M.; Mirza, S.; Koradia, V.; Gordon, K.C.; Rantanen, J. Solid form screening-a review. Eur. J. Pharm. Biopharm. 2009, 71, 23-37. [CrossRef] [PubMed]

5. Morris K., R.; Rodríguez-Hornedo, N. Encyclopaedia of Pharmaceutical Technology, 3rd ed.; Swarbrick, J., Boylan, J., Eds.; Marcel Dekker: New York, NY, USA, 1993; pp. 393-440.

6. Tiana, F.; Qua, Q.; Zimmermann, A.; Munka, T.; Jørgensend, A.C.; Rantanena, Y. Factors affecting crystallization of hydrates. J. Pharm. Pharmacol. 2010, 62, 1534-1546. [CrossRef] [PubMed]

7. Xu, Y.; Jiang, L.; Huang, Y.; Wang, J.R.; Mei, X. Solid-State Characterization and Transformation of Various Creatine Phosphate Sodium Hydrates. J. Pharm. Sci. 2014, 103, 3688-3695. [CrossRef]

8. Hickey, M.B.; Peterson, M.L.; Manas, E.S.; Alvarez, J.; Haeffner, F.; Almarsson, O. Hydrates and Solid-State Reactivity: A Survey of $\beta$-Lactam Antibiotics. J. Pharm. Sci. 2007, 96, 1090-1099. [CrossRef] 
9. Martins Santos, O.M.; Dias Reis, M.E.; Tavares Jacon, J.; Esselin de Sousa Lino, M.; Savioli Simões, J.; Doriguetto, A.C. Polymorphism: An evaluation of the potential risk to the quality of drug products from the Farmácia Popular Rede Própria. Braz. J. Pharm. Sci. 2014, 50, 1-24. [CrossRef]

10. Aitipamula, S.; Vangala, V.R. X-Ray Crystallography and its Role in Understanding the Physicochemical Properties of Pharmaceutical Cocrystals. Indian Inst. Sci. 2017, 97, 227-243. [CrossRef]

11. Beloborodova, A.A.; Minkov, V.S.; Rychkov, D.A.; Rybalova, T.V.; Boldyreva, E.V. First Evidence of Polymorphism in Furosemide Solvates. Growth Des. 2014, 17, 2333-2341. [CrossRef]

12. Maestrelli, F.; Rossi, P.; Paoli, P.; De Luca, E.; Mura, P. The role of solid state properties of flufenamic acid. J. Pharm. Biom. Anal. 2020, 14, 113058-113066. [CrossRef]

13. Rossi, P.; Paoli, P.; Ienco, A.; Biagi, D.; Valleri, M.; Conti, L. A new crystal form of the NSAID dexketoprofen. Acta Cryst. Sect. C 2019, 75, 783-792. [CrossRef]

14. Paoli, P.; Rossi, P.; Chelazzi, L.; Altamura, M.; Fedi, V.; Giannotti, D. Solid State Investigation and Characterization of a Nepadutant Precursor: Polymorphic and Pseudopolymorphic Forms of MEN11282. Cryst. Growth Des. 2016, 16, 5294-5304. [CrossRef]

15. Drebushchak, T.N.; Mikhailenko, M.A.; Brezgunova, M.E.; Shakhtshneider, T.P.; Kuznetsova, S.A. Crystal Structure Of Betulin Ethanol Solvate. J. Struct.Chem. 2010, 51, 798-801. [CrossRef]

16. Drebushchak, V.A.; McGregor, L.; Rychkov, D.A. Cooling rate "window" in the crystallizationof metacetamol form II. J. Therm. Anal. Calorim. 2017, 127, 1807-1814. [CrossRef]

17. Paoli, P.; Rossi, P.; Macedi, E.; Ienco, A.; Chelazzi, L.; Bartolucci, G.L.; Bruni, B. Similar but Different: The Case of Metoprolol Tartrate and Succinate Salts. Cryst. Growth Des. 2016, 16, 789-799. [CrossRef]

18. Rossi, P.; Paoli, P.; Chelazzi, L.; Conti, L.; Bencini, A. Metroprolol Fumarate: Crystal Structure from Powder X-ray Diffraction Data and Comparison with the Tartrate and Succinate Salts. Cryst. Growth Des. 2018, 18, 7015-7026. [CrossRef]

19. Rossi, P.; Macedi, E.; Paoli, P.; Bernazzani, L.; Carignani, E.; Borsacchi, S.; Geppi, M. Solid-Solid Transition between Hydrated Racemic Compound and Anhydrous Conglomerate in Na-Ibuprofen: A Combined X-ray Diffraction, Solid-State NMR, Calorimetric, and Computational Study. Cryst. Growth Des. 2014, 14, 2441-2452. [CrossRef]

20. McGregor, L.; Rychkov, D.A.; Coster, P.L.; Day, S.; Drebushchak, V.A.; Achkasov, A.F.; Nichol, G.S.; Pulham, C.R.; Boldyreva, E.V. A new polymorph of metacetamol. CrystEngComm 2015, 17, 6183-6192. [CrossRef]

21. Yang, P.; Qin, C.; Du, S.; Jia, L.; Qin, Y.; Gong, J.; Wu, S. Crystal Structure, Stability and Desolvation of the Solvates of Sorafenib Tosylate. Crystals 2019, 9, 367. [CrossRef]

22. Tarakanova, E.G.; Voloshenko, G.I.; Kislina, I.S.; Mayorov, V.D.; Yukhnevich, G.V.; Lyashchenko, A.K. Composition and Structure of Hydrates Formed in Aqueous Solutions of Formic Acid. J. Struct.Chem. 2019, 60, 255-267. [CrossRef]

23. Rossi, P.; Paoli, P.; Milazzo, S.; Chelazzi, L.; Ienco, A.; Conti, L. Investigating Differences and Similarities between Betaxolol Polymorphs. Crystals 2019, 9, 509. [CrossRef]

24. Paoli, P.; Milazzo, S.; Rossi, P.; Ienco, A. Rationalization of Lattice Thermal Expansion for Beta-Blocker Organic Crystals. Crystals 2020, 10, 350. [CrossRef]

25. Rossi, P.; Paoli, P.; Chelazzi, L.; Conti, L.; Bencini, A. The solid-state structure of the $\beta$-blocker metoprolol: A combined experimental and in silico investigation. Acta Cryst. 2019, C75, 87-96. [CrossRef]

26. Rychkov, D.A. A Short Review of Current Computational Concepts for High-Pressure Phase Transition Studies in Molecular Crystals. Crystals 2020, 10, 81. [CrossRef]

27. Rychkov, D.A.; Stare, J.; Boldyreva, E.V. Pressure-driven phase transition mechanisms revealed by quantum-chemistry: L-serine polymorphs. Phys. Chem. Chem. Phys. 2017, 19, 6671-6676. [CrossRef] [PubMed]

28. Giovannoni, M.P.; Schepetkin, I.; Quinn, M.T.; Cantini, N.; Crocetti, L.; Guerrini, G.; Iacovone, A.; Paoli, P.; Rossi, P.; Bartolucci, G.; et al. Synthesis, biological evaluation, and molecular modelling studies of potent human neutrophil elastase (HNE) inhibitors. J. Enz. Inhib. Med. Chem. 2018, 33, 1108-1124. [CrossRef] [PubMed]

29. Giovannoni, M.P.; Crocetti, L.; Cantini, N.; Guerrini, G.; Vergelli, C.; Iacovone, A.; Teodori, E.; Schepetkin, I.; Quinn, M.T.; Ciattini, S.; et al. New 3-unsubstituted isoxazolones as potent human neutrophil elastase inhibitors: Synthesis and molecular dynamic simulation. Drug Develop. Res. 2020, 81, 338-349. [CrossRef] [PubMed] 
30. Hanna, M.; Moon, J.Y. A review of dexketoprofen trometamol in acute pain. Curr. Med. Res. Opin. 2019, 35, 189-202. [CrossRef]

31. Bosch, M.; Mannucci, S.; Torras, E.; Falorni, R.; Gonzales, J.M. Polymorphic forms of dexketoprofen trometamol, preparation and pharmaceutical compositions thereof. European Patent EP1739072 A1, March 2007.

32. Farshi, F.; Soylemez, S.; Koc, F.; Durmus, S. A process for preparing dexketoprofen trometamol form A and form B crystals. International Patent WO2011/001213 A1, June 2009.

33. Rossi, P.; Paoli, P.; Chelazzi, L.; Milazzo, S.; Biagi, D.; Valleri, M.; Ienco, A.; Valtancoli, B.; Conti, L. Relationships between Anhydrous and Solvated Species of Dexketoprofen Trometamol: A Solid-State Point of View. Cryst. Growth Des. 2020, 20, 226-336. [CrossRef]

34. Bruker. BrukerAPEX2; Bruker AXS Inc.: Madison, WI, USA, 2012.

35. Bruker. Bruker SAINT; Bruker AXS Inc.: Madison, WI, USA, 2012.

36. Burla, M.C.; Caliandro, R.; Camalli, M.; Carrozzini, B.; Cascarano, G.L.; Da Caro, L.; Giacovazzo, C.; Polidori, G.; Spagna, R. An improved tool for crystal structure determination and refinement. J. Appl. Crystallogr. 2005, 38, 381-388. [CrossRef]

37. Sheldrick, G.M. Crystal structure refinement with SHELXL. Acta Crystallogr. Sect. C Struct. Chem. 2015, 71, 3-8. [CrossRef]

38. Nardelli, M. PARST95 - an update to PARST: A system of Fortran routines for calculating molecular structure parameters from the results of crystal structure analyses. J. Appl. Crystallogr. 1995, 28, 659. [CrossRef]

39. Farrugia, L. WinGX and ORTEP for Windows: An update. J. Appl. Cryst. 2012, 45, 849-854. [CrossRef]

40. Macrae, C.F.; Bruno, I.J.; Chisholm, J.A.; Edgington, P.R.; McCabe, P.; Pidcock, E.; Rodriguez-Monge, E.; Taylor, R.; van de Streek, J.; Wood, P.A.; et al. Mercury CSD 2.0-New Features for the Visualization and Investigation of Crystal Structures. J. Appl. Crystallogr. 2008, 41, 466-470. [CrossRef]

41. Discovery Studio 2019 Client; BIOVIA: San Diego, CA, USA, 2019.

42. Turner, M.J.; McKinnon, J.J.; Wolff, S.K.; Grimwood, D.J.; Spackman, P.R.; Jayatilaka, D.; Spackman, M.A. CrystalExplorer17 (2017); University of Western Australia: Perth, Australia, 2017.

43. Dovesi, R.; Erba, A.; Orlando, R.; Zicovich-Wilson, C.M.; Civalleri, B.; Maschio, L.; Rérat, M.; Casassa, S.; Baima, J.; Salustro, S.; et al. Quantum-mechanical condensed matter simulations with CRYSTAL. WIRES Comput. Mol. Sci. 2018, 8, e1360. [CrossRef]

44. Sure, R.; Grimme, S. Corrected small basis set Hartree-Fock method for large systems. J. Comput. Chem. 2013, 34, 1672-1685. [CrossRef]

45. Cutini, M.; Civalleri, B.; Corno, M.; Orlando, R.; Brandenburg, J.G.; Maschio, L.; Ugliengo, P. Assessment of different quantum mechanical methods for the prediction of structure and cohesive energy of molecular crystals. J. Chem. Theory Comput. 2016, 12, 3340-3352. [CrossRef]

46. IUPAC. Compendium of Chemical Terminology, 2nd ed.; the "Gold Book"; McNaught, A.D., Wilkinson, A., Eds.; Blackwell Scientific Publications: Oxford, UK, 1997.

47. Groom, C.R.; Bruno, I.J.; Lightfoot, M.P.; Ward, S.C. The Cambridge Structural Database. Acta Cryst. Sect. B 2016, 72, 171-179.

48. Etter, M.C.; MacDonald, J.C.; Bernstein, J. Graph-set analysis of hydrogen-bond patterns in organic crystals. Acta Crystallogr., Sect. B Struct. Sci. 1990, 46, 256-262. [CrossRef]

49. Kitaigorodskii, A.I. Organic Chemical Crystallography; Consultants Bureau: New York, NY, USA, 1961; pp. 106-110.

50. Werner, J.E.; Swift, J.A. Data mining the Cambridge Structural Database for hydrate-anhydrate pairs with SMILES strings. CrystEngComm 2020. [CrossRef]

51. Morris, K.R. Structural Aspects of Hydrates and Solvates. In Polymorphism in Pharmaceutical Solids; Brittain, H.G., Ed.; Marcel Dekker Inc.: New York, NY, USA, 1999; pp. 126-179.

(C) 2020 by the authors. Licensee MDPI, Basel, Switzerland. This article is an open access article distributed under the terms and conditions of the Creative Commons Attribution (CC BY) license (http://creativecommons.org/licenses/by/4.0/). 